\title{
O que faz "Educacional" no marketing digital de games empresariais?
}

DOI: http://dx.doi.org/10.21165/el.v49i3.2737

\section{Bruna Caires Delgado'}

\section{Resumo}

Uma empresa privada que oferece produtos/serviços voltados para o Programa de Inovação do Cooperativismo Paranaense divulga-se, em seu site institucional, com a seguinte assinatura: "Nome da empresa | Tecnologia e Inovação em Gamificação Empresarial, Educacional e Recrutamento e Seleção". Observando a enunciação que a empresa faz de si, em um espaço de marketing digital, um fato discursivo importante não deixa de inquietar: o que faz "Educacional" nessa formulação? Buscando compreender que discursividade(s) sustenta(m) a forma material "Educacional", este artigo apresenta reflexões teóricas da Análise de Discurso Materialista.

Palavras-chave: análise de discurso materialista; educação; games empresariais; metatítulo; marketing digital.

1 Universidade Estadual de Campinas (UNICAMP), Campinas, São Paulo, Brasil; brunacdelgado@gmail.com; http://orcid.org/0000-0002-4252-7762 


\section{Qu'est-ce que "Educatif" fait dans le Marketing Numérique de Games d'Entreprise?}

\section{Résumé}

Une entreprise privée qui propose des produits/services adaptés au Programme d'Innovation Coopérative Paranaense se révèle sur son site web institutionnel avec la signature suivante: "Nom de l'enterprise I Technologie et Innovation dans la Gamification d'Entreprise, Éducatif et Recrutement et Sélection". En observant l'énonciation que cette entreprise fait d'elle-même, dans un Titre, dans un espace de digital marketing, un fait discursif important ne cesse de nous inquiéter: qu'est-ce que «Éducatif» dans cette formulation? Pour comprendre quelle(s) discursivité(s) sous-tendent la forme matérielle «Éducatif», cet article présente des réflexions théoriques de l'Analyse du Discours Matérialiste.

Mots-clés: analyse du discurs metérialiste; education; games d'entreprise; méta-titre; marketing númerique.

\section{Iniciando um trajeto}

Este artigo de análise é uma aproximação com o meu trabalho de tese, filiado teoricamente à Análise de Discurso Materialista (AD), trabalhada por Michel Pêcheux. Mesmo que sob a forma de um projeto inicial, considero o funcionamento amplo, heterogêneo e polêmico da "educação", quando deslocada do seu lócus institucional (a escola), para o espaço de trabalho. Em minhas reflexões para a tese, tenho nomeado essa prática educacional do sujeito-trabalhador como "escolarização do/no espaço de trabalho". Também penso, nessas reflexões, que a articulação entre educação e tecnologia pode produzir sentidos nessa prática.

Para este artigo, em especial, observo um fato discursivo importante, que chama atenção para um tema que pode contribuir para as pesquisas na área em questão, o Serviço Nacional de Aprendizagem do Cooperativismo (SESCOOP) ${ }^{2}$, uma entidade do Sistema S, tem como parceira, no Programa de Inovação do Cooperativismo Paranaense, uma empresa privada que atende o setor de Recursos Humanos, que, por sua vez, se

2 Criado com a Medida Provisória no 1.715, em 3 de setembro de 1998, e regulamentado pelo Decreto no 3.017, de 6 de abril de 1999. Segundo o site oficial, "O escopo de ações do $S$ do cooperativismo abrange cursos de curta e longa duração, incluindo, graduação e especialização, treinamentos, seminários, palestras, workshops, dias de campo, reuniões técnicas e fóruns e outros projetos voltados à capacitação profissional, meio ambiente, geração de renda e melhoria da qualidade de vida". Disponível em: http://www.paranacooperativo.coop.br/ppc/index.php/2011-12-05-11-2914/transparenciaa. Acesso em: 30 set. 2019. 
enuncia em seu site institucional com o seguinte Título3: "Nome da empresa | Tecnologia e Inovação em Gamificação Empresarial, Educacional e Recrutamento e Seleção". Observando a enunciação que a empresa faz de si, os sentidos possíveis para o que seria "Educacional" perturbam, de modo que a orientação de uma pergunta não deixa de inquietar: "Que discursividade(s) sustenta(m) a forma material 'Educacional' nessa formulação?". Considerando que o uso de "Gamificação" é adotado no espaço de trabalho como "instrumento tecnológico" de acesso ao sujeito-trabalhador, neste estudo, tem-se que "Educacional" aponta, entre outros sentidos, para os sentidos de adequação.

Neste trabalho, apresento reflexões teóricas da AD sobre forma material e processo de formação do discurso, no qual entendo o funcionamento do marketing digital${ }^{4}$ como constitutivo.

\section{"Educacional" como uma forma material}

$A A D$, teoria e instrumento de leitura e de interpretação de textos que me orienta, tem como um dos seus princípios gerais, relevante para este trabalho, a concepção de materialidade discursiva. A partir das reflexões de Orlandi (2015) sobre os processos discursivos nos quais inscrevem-se as práticas e os saberes, entende-se que a materialidade discursiva é de existência sócio-histórica. Ou seja, ela não é sinônima de "língua, nem de literatura, nem mesmo as "mentalidades" de uma época, mas [...] remete às condições verbais de existência dos objetos (científicos, estéticos, ideológicos...) em uma conjuntura histórica dada" (ORLANDI, 2015, p. 151).

Para a autora, os "objetos de saber" são sempre determinados enquanto objetos históricos e, também, ideológicos. Analisando alguns objetos, Orlandi (2015, p. 157) mostra que eles existem ao se inscreverem em formações discursivas, "como uma unidade dividida, suscetível de se inscrever em um ou outro efeito conjuntural, politicamente sobredeterminado". Essa posição rejeita a ideia de que há uma estrutura sêmica do objeto que pode variar ao ser aplicado "nesta" ou "naquela" situação. Para a AD, a linguagem toma corpo pela materialização da ideologia no discurso que, por sua vez, materializa-se na língua.

Encaro que a referência discursiva do objeto de saber "Educacional" já é construída em formações discursivas (técnicas, morais, políticas...) que combinam seus efeitos em efeitos de interdiscurso, uma memória discursiva de ordem não cronológica e

3 Trato "Título" com letra maiúscula por estar tomando um elemento de leitura da semântica computacional, "Meta-Título", como corpus. Tal questão será retomada neste texto.

4 Entendemos o Marketing Digital como um conjunto de técnicas, estratégias, ferramentas e ações para atrair e reter clientes por meio do processamento de dados digitais. 
inconsciente, quando materializada, no caso deste estudo, no Título em questão. Assim, trabalho com a forma material tal como proposta por Orlandi (2015), para quem a língua não é um conceito "abstrato", não se separa forma e conteúdo e procura-se compreender a língua não só em sua estrutura, mas como acontecimento. Para Pêcheux (2008), a língua é material porque é sempre histórica. Sendo assim, o valor ${ }^{5}$ de uma materialidade discursiva como "Educacional" só existe na história e em uma certa história.

O trajeto de compreensão construído aqui para a questão "O que faz Educacional?" no Título já apresentado, buscou entender como essa materialidade significa. Ou seja, como é o funcionamento do sistema de restrição/abertura de sentidos que está operando sobre/com ela.

Para tanto, é preciso compreender, no Título mencionado, que discursividade(s) sustenta(m) a forma material "Educacional", levando em consideração que é na relação com outras palavras em um sistema chamado "processo de produção do discurso" que constituição, formulação e circulação (ORLANDI, 2012) se imbricam materializando sentidos.

\section{Processo de produção do discurso, constituição, formulação e circulação}

Pode-se pensar o processo de produção do discurso de maneira mais aprofundada, retomando as aproximações feitas por Orlandi (2012), especificamente, de: constituição, que se dá a partir da memória do dizer, fazendo intervir o contexto histórico ideológico mais amplo; de formulação como uma forma linearizada do dizer, em que há a atualização da memória discursiva, e, por ser ela que materializa o discurso em texto, como o intradiscurso, é um dizer respeito a circunstâncias de enunciação específicas; e de circulação, como o interdiscurso, um espaço em que os textos se mostram, ou seja, de que forma o discurso é regulado, quais são suas fronteiras. Mais especificamente, sobre a formulação e a constituição dos discursos, a autora afirma que: "Todo dizer (intradiscurso, dimensão horizontal, formulação) se faz num ponto em que (se) atravessa o (do) interdiscurso (memória, dimensão vertical estratificada, constituição)" (ORLANDI, 2012, p. 12).

Considerando o processo de produção do discurso, nesta seção, chamo atenção para as condições de produção. Em AD, o analista "relaciona a linguagem à sua exterioridade" (ORLANDI, 2015, p. 14), por isso, as condições de produção - contextos imediato e amplo - são fundamentais para a compreensão do sujeito e da situação, pois deixam seus vestígios na forma material da língua.

5 Haroche, Henry e Pêcheux (2008) desenvolvem a semântica não tratada por Saussure em sua obra de destaque, a partir dos conceitos de analogia e de valor, buscando caminhos para o estudo da significação. 
Em um contexto imediato, é importante olhar para a formulação do Título e sua circulação na divulgação do site institucional de uma empresa privada. A forma contemporânea de se criarem estratégias de venda passa a envolver o ambiente on-line, o marketing digital. Por esse motivo, os sites de busca, como o Google, por exemplo, se tornam espaço de compra/interpretação, isto é, encontro entre usuário/cliente e produto/serviço. É a partir da busca feita pelo usuário que esses sites tomam os Títulos como um dispositivo de análise da semântica computacional, para dar respostas/resultados.

Os Títulos, por sua vez, são formulados por palavras-chave ${ }^{6}$. As palavras-chave que podem estar no que a linguagem computacional considera como "mesmo campo semântico" são capazes de serem previamente medidas por meio de ferramentas algorítmicas (que apontam o volume de buscas já feitas pelo usuário). Isso quer dizer que o algoritmo indica quais são as palavras-chave mais buscadas pelo usuário, de modo que é a partir dessa "necessidade" que algumas palavras são relevantes e outras não para o marketing digital. Por isso, para que as empresas interessadas possam atingir seus compradores (chamados de "buyer persona") que, no caso da nossa análise, são outras empresas, elas descrevem e definem seus websites usando de estratégias de Marketing que partem da consideração dessas palavras-chave (keywords), com bastante ênfase nos Títulos, espaço de maior destaque na busca.

Em resumo, a formulação desse Título faz parte do funcionamento do Marketing Digital, que tem como objetivo, além de descrever e definir o conteúdo do website, levar o usuário a determinada empresa, por meio do assunto/termo pesquisado. Com tal discussão em consideração, retoma-se o Título recortado para a presente análise.

Quadro 1. Resultado de uma busca-Google

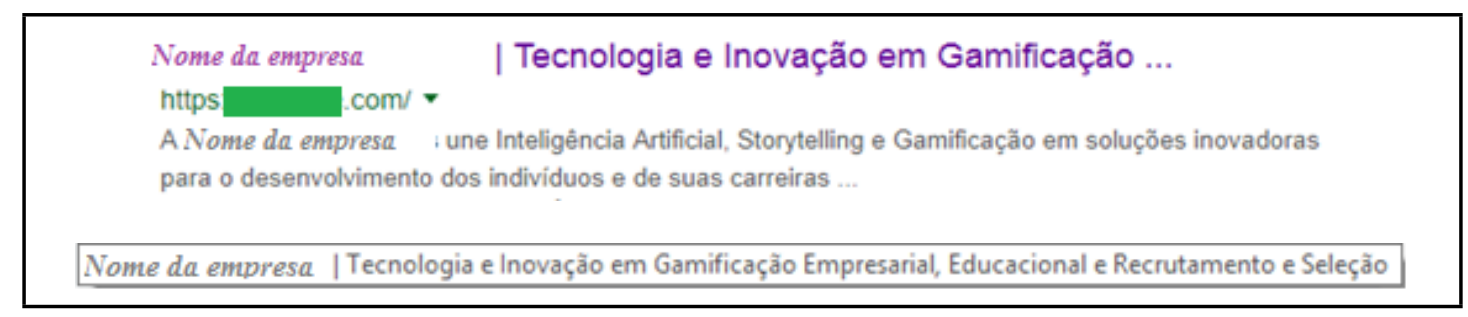

Fonte: Busca feita no Google, pela autora

Interessante notar que o espaço fornecido pela Google para a circulação do Título é de no máximo 70 caracteres. Por conta desse limite, no Quadro 1, a Página de Resultado (Seaching Engine Result Pages - SERPS) não exibe todo o Título do site por completo,

6 Palavras que são rastreadas nas URL, nas legendas de imagens, vídeos e áudios, nos links internos e, principalmente, no meta-título e na meta-descrição do site. Isso é feito para que o site de busca possa levar esse usuário a ter informações relacionadas ao termo pesquisado. 
pois ele ultrapassa o número de caracteres exigidos. Abaixo do Título, temos o link do site, e logo abaixo está a meta-descrição, que também funciona com restrições, dessa vez de 160 caracteres. Esse limite de palavras, discursivamente tratado como espacialização da superfície linear do texto, não se restringe a um mero procedimento técnico, ao contrário, estabelece uma relação com os sentidos que são formulados em torno de uma definição. Os percursos de dizeres esbarram na régua medidora dos Títulos, em que a formulação se envolve com o limite de caracteres que um Título pode ter, por conta da sua circulação.

Se o Marketing Digital faz parte das condições de produção específicas do que estamos analisando, é preciso indicar que as condições de produção amplas do discurso, em que tomamos o objeto de análise, consideram que os sentidos de "Educacional" são atravessados pelas mudanças das relações no tempo-espaço de trabalho.

Aires, Moreira e Freire (2017), em um estudo sobre a Revolução $4.0^{7}$ e a Gestão do Conhecimento, afirmam que as exigências para o trabalhador são afetadas pelas mudanças nos sistemas de produção, por isso, a Educação Corporativa (EC) "evolui" para Universidade Corporativa (UC), no fim do século XX, no Brasil, para alcançar a mudança do perfil do trabalhador e garantir as vantagens competitivas das empresas. "Sendo a educação corporativa uma importante área das organizações, responsável em gerenciar o desenvolvimento das capacidades requeridas da força de trabalho visando à construção da sonhada vantagem competitiva sustentável" (AIRES; MOREIRA; FREIRE, 2017, p. 231). As autoras, considerando os processos organizacionais da Gestão de Conhecimento, afırmam que as empresas, na Revolução 4.0, têm que lidar com um novo tipo de conhecimento; criar conhecimentos em seus trabalhadores em espaços físicos, virtuais ou mentais; e fazer com que trabalhadores comuniquem seus conhecimentos.

\begin{abstract}
Após a capturae/ou criação do conhecimento, sua codificação e compartilhamento, é imprescindível utilizá-lo, no intuito de diminuir desperdício de tempo e recursos na busca por conhecimento. A chave para o tão almejado sucesso organizacional é a capacidade de capturar conhecimento, transformá-lo em aprendizagem organizacional e reutilizá-lo. (AIRES; MOREIRA; FREIRE, 2017, p. 233).
\end{abstract}

É sobre esse deslizamento da prática de educar/capacitar - formal e informalmente - do seu lócus institucional (escolas, graduações, pós-graduações, cursos técnicos, cursos profissionalizantes, etc.) para o espaço de trabalho, somada à forma tecnológica de se pensar o conhecimento, que faço uma aproximação com o que propõe Morello (2004, p. 31):

76 As autoras fazem a seguinte divisão: $1^{\text {a }}$ Revolução Industrial, metade do século XVIII até metade do XIX, substitui a produção artesanal pela máquina e o vapor; $2^{a}$ Revolução Industrial, meados do século XIX e primeira metade do século XX, conta com o advento da energia elétrica, das linhas de produção e da produção em massa; $3^{a}$ Revolução Industrial, na segunda metade do século $X X$, implementa componentes eletrônicos e automação dos processos produtivos; e $4^{a}$ Revolução Industrial, com início no século XXI, é caracterizada pela digitalização da produção. 
Pela articulação ao modelo informacional, as políticas científicas ou educacionais confrontam-se com a intensa elaboração de técnicas e tecnologias ligadas à definição de formatos e procedimentos para criação de produtos para a rede, à proposição de modelos para a gestão de conhecimentos e a produção de condições para que o conhecimento tecnologizado aconteça.

Entendo que esse cenário seja resultado de "uma história de histórias" (SILVA, 2015) que foi se escrevendo a partir e ao longo da urbanização do Brasil. A substituição do modelo agroexportador pelo modelo de industrialização, durante o governo de Vargas (tenho me dedicado ao período entre 1920-1940), é um acontecimento que, ligado à incontingência da história, não isoladamente, nem naturalmente, incide na construção da Educação enquanto necessidade de tornar o povo brasileiro apto para as "novas formas de trabalho". O momento inaugura, no Brasil, as parcerias público-privadas, entre as elites industriais e o Estado, para a Educação Profissional. Nessas parcerias, cabe aos industriais "educar" os trabalhadores e ao Estado "financiar" essa educação.

Quanto à era de Vargas, trata-se de um momento entendido como a construção de uma unidade nacional brasileira pautada na ideia de um país moderno e industrial que, para a formação de trabalhadores, exercia controle da cultura e do conhecimento (ORLANDI, 2009)8. Há, portanto, uma forte relação entre educação e trabalho que acompanha a história das sociedades capitalistas.

No entanto, há deslocamentos e não apenas repetições nessa história, por isso, não há como fazer essa discussão neste artigo de modo alongado, até porque se trata de parte do que venho pesquisando em meu doutoramento. O que aqui gostaria de salientar é que importa, para a compreensão da presença do "Educacional" no referido Título, levar em consideração o que nos diz Pêcheux (2015b) sobre espaço de memória. O autor afirma o seguinte:

[...] uma memória não poderia ser concebida como uma esfera plena, cujas bordas seriam transcendentais históricos e cujo conteúdo seria um sentido homogêneo, acumulado ao modo de um reservatório: é necessariamente em um espaço móvel de divisões, de disjunções, de deslocamentos e de retomadas, de conflitos de regularização... um espaço de desdobramentos, réplicas, polêmicas e contradiscursos. (PÊCHEUX, 2015b, p. 50).

Em uma concepção materialista de "memória", os efeitos do interdiscurso não se resolvem em um ponto de integração, mas em contradições (PECHÊUX, 2015a). Consideramos,

8 Em outro trabalho que estou desenvolvendo, entendo que os sentidos de "escolarização do/no espaço de trabalho", a partir da Era Vargas e da pedagogia do uno, se tornam um gesto inicial do termo no Brasil. 
assim, uma memória discursiva para observar um retorno do processo de escolarização quando se trata de "educar" o sujeito-trabalhador. Efetivamente, o ato de "preparação dos indivíduos" não mais cessa nas instituições escolares: "todos" precisam ser "educados", constantemente, também, no espaço de trabalho. Assim, ao se considerar a contemporaneidade e seus processos de conformação, como o Programa de Inovação do Cooperativismo Paranaense, observo que uma memória discursiva de escolarização esbarra no sujeito-trabalhador.

Lembrando Pfeiffer (2011) e sua proposição de que os processos de urbanização e de escolarização são indissociáveis e que na relação entre eles, por sua vez, configuram-se sentidos para o sujeito urbano escolarizado (e ainda que em fase inicial de formulação), estou estabelecendo uma relação com o processo de escolarização de um modo mais geral, afetando nossa relação com os imaginários de Trabalho. Vejo reverberar uma memória escolarizada de educação, que, por sua vez, é ligada ao urbano e à construção da evidência de que seja necessário "preparar os indivíduos para acompanharem a sociedade em acelerados processos de mudança" (PFEIFFER, 2011, p. 154).

\section{Possíveis análises para o Título}

O fato discursivo importante é justamente compreender como se sustenta "Educacional" como forma material no Título: "Nome da empresa | Tecnologia e Inovação em Gamificação Empresarial, Educacional e Recrutamento e Seleção". Por isso, esta análise se inicia observando os efeitos de sentidos sustentados pelas discursividades que nelas funcionam.

Em um primeiro gesto analítico, senti necessidade de compreender, no processo discursivo, sobre como se dá essa "soma de palavras-chave", constitutiva da formulação do Título, chamado em marketing digital de "Meta-Título". Sendo assim, para a constituição da análise, além dos conceitos da AD, tomo, também, o trabalho de Guimarães (2009), da Semântica da Enunciação", sobre a Enumeração ${ }^{10}$, teoria que trata dessa "soma" formando unidades de sentido.

Por sua vez, as compreensões de enumeração são tomadas como um ponto de partida para a compreensão dos efeitos discursivos ligados a esse funcionamento. A ideia é olhar para um fenômeno sintático para compreender os efeitos discursivos - o que pressupõe considerar a língua na história em seu funcionamento político e ideológico. Pêcheux (2015, p. 136), ao fazer essas aproximações, afirma que este "é ponto máximo do efeito discursivo, enquanto ponto de contato entre o linguístico e o ideológico".

9 Importante ressaltar que o propósito, aqui, considera os traçados paralelos entre as teorias, que identifica possíveis proximidades (como a compreensão da historicidade), lembrando, no entanto, que nosso objeto de estudo é o funcionamento do discurso, que será retomado no texto.

10 “[...] A enumeração apresenta um conjunto de expressões como modos de apresentar cada um dos aspectos que juntos formam uma unidade de sentido" (GUIMARÃES, 2009, p. 58). 
Tendo como base o texto como "vestígio da materialidade" (ORLANDI, 2012), notamos que ele funciona como unidade de análise que se estabelece, pela historicidade, como unidade de sentido em relação à situação. No Título, as marcas "Gamificação", "Empresarial", "Educacional", "Recrutamento e Seleção" mostram como as articulações enunciativas (GUIMARÃES, 2009) se movimentam, produzindo a presença de diferentes sentidos marcados por uma relação de sustentação que para nós é discursiva. Para Guimarães (2009), a articulação é o acúmulo de contiguidade entre os elementos do enunciado (dependência ${ }^{11}$, coordenação ${ }^{12}$ e incidência); enquanto a reescrituração vem redizer o que já foi dito entre elementos distantes envolvendo sempre um diferente (repetição, substituição, elipse, expansão, condensação e definição).

Figura 1. Título (Meta-Título)

Nome da empresa | Tecnologia e Inovação em Gamificação Empresarial, Educacional e Recrutamento e Seleção

Fonte: Busca-Google feita pela autora

Com base na figura acima, e nas proposições de Guimarães (2009), se a barra ("I") fosse considerada um elemento de reescrituração, lendo-a sob o mesmo funcionamento dos "dois pontos", o que está depois da barra reescreveria, de forma diferente, o que está antes. Além disso, estariam articuladas em uma relação de coordenação as formulações: "Tecnologia e Inovação", "Educacional e Recrutamento e Seleção", de modo que os pares e o trio estariam organizados como um elemento de mesma natureza pela presença material do "e". Ainda, estaria em relação de dependência o par "Gamificação Empresarial", caracterizado por ser, no conjunto, um só elemento. Retornarei a essas relações mais adiante.

Considerando a relação da língua com o interdiscurso, essas unidades textuais tomadas como unidades de análise - são o nosso acesso ao discurso, ao trabalho dos sentidos. Por isso, observar como o discurso se textualiza em forma de descrição e definição é entender que terminologias propostas nos Títulos são integradas a um texto dentro do qual elas se estabilizam. Como a língua não é suscetível a regular a produção e a interpretação dos enunciados (PÊCHEUX, 2015), vamos observar os funcionamentos discursivos a partir da elaboração de paráfrases, como método de análise da disciplina à qual estou filiada.

11 “...] dependência se dá quando os elementos contíguos se organizam por uma relação que constitui, no conjunto, um só elemento" (GUIMARÃES, 2009, p. 51).

12 "....] coordenação é aquela que toma elementos de mesma natureza e os organiza como se fossem um só da mesma natureza de cada um dos constituintes" (Idem). 


\section{Gestos de paráfrases}

Em $A D$, quando tratamos o texto, nos afastamos das técnicas algorítmicas relacionadas aos bancos de dados, como foi apresentado em relação à busca do Título. Acontece que a materialidade dos processos discursivos se relaciona com o real da língua e com o tipo de pergunta que está em evidência no processo de análise (PECHÊUX, 2015).

De fato, criar paráfrases é um processo heurístico que trata do retorno do mesmo em condições e relações distintas com a memória. $A A D$, pela sua natureza material, permite que o analista toque a "forma histórica da significação na compreensão de cada gesto da interpretação" (ORLANDI, 2012, p. 29), ou seja, o analista de discurso, considerando que o sentido de uma palavra só se dá na relação com contexto (que é variável), descreve (faz paráfrases) e, também, interpreta. Por isso, ao usar da paráfrase, evito a pretensão de mostrar a "verdade" dos sentidos. Assim, convido o leitor a ficar atento às propostas de paráfrase e aos movimentos dos sentidos, no Quadro 2, a seguir:

Quadro 2. Paráfrases

(1) Nome da empresa | Tecnologia e Inovação em Gamificação Empresarial, Educacional e Recrutamento e Seleção.

(1a) A Nome da empresa produz Tecnologia e Inovação.

(1b) A Nome da empresa produz Tecnologia e Inovação em Gamificação Empresarial.

(1c) A Nome da empresa produz Tecnologia e Inovação em Gamificação Educacional.

(1d) A Nome da empresa produz Tecnologia e Inovação em Recrutamento e Seleção.

(1e) A Nome da empresa produz Tecnologia e Inovação em Gamificação para Recrutamento e Seleção.

(1f) A Nome da empresa produz Tecnologia e Inovação em Gamificação Empresarial e Educacional.

(1g) A Nome da empresa produz Tecnologia e Inovação em Gamificação Empresarial e em Recrutamento e Seleção.

(1h) A Nome da empresa produz Tecnologia e Inovação em Gamificação Educacional e em Recrutamento e Seleção.

Fonte: Elaboração própria

Se, nesta análise, a barra fosse entendida enquanto pontuação, por um olhar discursivo, poderia estar em concordância com Orlandi (2012, p. 110), a qual afirma que "as marcas da pontuação podem ser consideradas como manifestação da incompletude da linguagem". E, então, entre o dito e o não-dito, observar-se-ia a possibilidade dessa relação entre o que está antes e depois da barra. Como um texto faz sentido, também, por sua formulação - e se um Título de um site institucional pressupõe descrição e definição - parece-me que os sentidos do que "é" a empresa são reescritos (GUIMARÃES, 2009) de 
forma diferente. A substituição da barra pelo verbo, no movimento parafrástico, se dá, pois, pela compreensão de que há a enumeração do que se oferece enquanto produtos. Dito de outro modo, significa dizer que a empresa é definida por meio de seus produtos, pois eles a definem, em um processo metonímico e metafórico; a empresa é o que ela "produz".

Agora passemos à observação do par "Tecnologia e Inovação", em que os termos aparecem em relação de aliança. A adição coordenada, segundo Guimarães (2009), seria característica de enumeração de elementos da mesma natureza, como se "Tecnologia" e "Inovação" fossem de uma mesma ordem, inseparáveis. Em AD, entendo que esse "e" dá corpo ao imaginário de unidade. Essa relação de aliança, ao lado de "em Gamificação", precisa ser considerada, afinal o emprego da preposição "em" configura um sentido de "meio, modo e forma" - muito restrito - para Inovação, circunscrita a desenvolvimento de equipamentos digitais. Essa restrição apaga, na história da humanidade, outras inovações tecnológicas como a escrita, por exemplo, que é tida como uma revolução tecnológica significativa para a forma de se fazer ciência, segundo Auroux (1992). Para Orlandi (2003), ainda que existam novas tecnologias da linguagem, elas são tecnologias da escrita, ou seja, elas se dão sob o funcionamento da escrita que afeta a organização da produção de conhecimento.

Ao lado desse funcionamento em que a empresa é o que produz, ela seria capaz de oferecer produtos "tecnológicos" que "materializam a inovação", ao passo que elas são inovações digitais. Assim, podemos passar a procurar compreender os produtos em si em seus processos de significação. Nesse sentido, pergunto: a Gamificação é Empresarial "e"/"ou" Educacional? É a partir da incompletude da noção de Acréscimo (ORLANDI, 2012), marcado pela vírgula, que efeitos discursivos apagam, no Título, de uma maneira geral, "que tipos de games" a empresa produz. A relação com a incompletude está o tempo todo sustentando a não busca por uma exaustividade.

A partir do movimento heurístico da paráfrase, tomado nas paráfrases " $1 b$ ", " $1 c$ " e " $1 f$ ", posso observar a repetição e o deslizamento de sentidos que deixam de coincidir, já que cada um deles (o que é Empresarial e Educacional) é tomado por uma área, que Ihe é externa. Por sua vez, a vírgula em "Empresarial, Educacional" indica que os termos não são equivalentes ou substituíveis, marcando o funcionamento de uma diferença/ combinação, já que os elementos têm uma relação frágil, se distanciando pelo próprio acréscimo e pela diferença. Acredito que nesse par funciona abundantemente a relação com outros discursos e não só dos elementos sintaticamente próximos e presentes; há uma "franja de um dizer indefinido, indeciso" (ORLANDI, 2012).

E haveria também Gamificação (Empresarial e/ou Educacional) em Recrutamento e Seleção, como formulado nas paráfrases " $1 \mathrm{~g}$ " e " $1 \mathrm{~h}$ "? Volto a tomar a exterioridade, para considerar que, na área de Recursos Humanos, Recrutamento e Seleção são processos 
psicotécnicos de acesso ao sujeito-trabalhador que se distinguem, mas que, juntos, funcionam como a ponta da busca/encontro de pessoas "adequadas" para cumprir requisitos de vagas de organizações. Embora "Selecionar e Recrutar" pareçam constituir uma coordenação, o que indicaria um mesmo funcionamento, "Recrutar" está relacionado a alistar e convocar, enquanto "Selecionar" se relaciona com o sentido de critérios.

Em suma, ao procurar compreender as discursividades inscritas no Título recortado para a presente análise, entendo que a empresa em questão toma a ferramenta "Gamificação" como técnica de "Tecnologia e Inovação" e por ela disponibiliza "Recrutamento e Seleção", em espaços "Empresariais". Se "Educação" estivesse inclusa nessas técnicas da "Gamificação", não apareceria como "Educacional". Um efeito de sentido possível é que a ferramenta não carrega práticas de educação, ela em si é educacional. Ainda que não seja explicitado como Gamificação pode ser Educacional, a ferramenta, pelo Título, parece dar conta do que Aires, Moreira e Freire (2017) afirmam ser necessidades para as empresas, atualmente: gerenciar o desenvolvimento das capacidades dos sujeitostrabalhadores, capturar, criar e/ou reutilizar o conhecimento.

Em AD entendemos "Educacional" como uma forma material, um objeto de saber determinado histórico. Portanto, a partir das análises das condições verbais de existências desse objeto no Título, nas conjunturas históricas dadas e pelas formações discursivas apresentadas à necessidade de administrar a relação de "Educacional" com a incompletude da linguagem, tem-se que o funcionamento do sistema de restrição/ abertura de sentidos que está operando sobre/com "Educacional" apontam para um espaço de memória de escolarização, ou de uma memória escolarizada de educação que, por sua vez, é ligada ao urbano e à construção da evidência de que os indivíduos precisam estar sempre adequados.

Ainda cabe reforçar que: esse Título é propaganda. Vender-se como "Educacional" parece ser bastante sedutor, principalmente para o espaço de trabalho da contemporaneidade.

\section{Resultados}

Diante das diversas considerações feitas ao longo do artigo, a inquietação causada pela pergunta "Que discursividades sustentam a forma material 'Educacional'?" foi abrandada, por meio da análise do recorte selecionado. Para compreender o processo discursivo inscrito na forma material "Educacional", para esta reflexão que foi apresentada, entendeuse a formulação da configuração textual do Título como importante para nossa análise, já que a circulação de "conteúdos" sobre serviços e produtos que a empresa oferece, a $d(r e)$ escreve e a define. 
Dificilmente o usuário digita o nome de uma empresa, ao buscar um serviço. Por isso, na busca por "Gamificação Empresarial", "Gamificação Educacional" ou "Recrutamento e Seleção", por exemplo, ele pode encontrar a empresa em questão, nos sites de busca. De fato, para além desse efeito há outros. Na análise, foi mostrado em uma tomada discursiva que "Tecnologia" é atravessada pela discursividade da "Inovação", sentidos se compõem, formando uma noção de aliança. Já a relação entre "Empresarial, Educacional" foi entendida como de proximidade e de afastamento, efeitos de contradição. E, ainda, "Recrutamento e Seleção", juntos, apontam para a presença de técnicas da (psicologia biológica) área de Recursos Humanos.

Sendo assim, a discursividade produz um efeito de divulgação e de suprimento de instrumentos pedagógicos no lócus do trabalho. O verbo "produzir" implica a oferta de um produto, e não a identidade da empresa: ela é, mas naquilo que ela oferece como serviço. De fato, "Educacional" é discursivizada a partir de uma projeção imaginária calcada na administração dos sentidos e, assim como Pfeiffer (2003) afırma sobre o efeito imaginário que configura o espaço escolar, acredito que o espaço de trabalho também vem sendo configurado enquanto um lócus autorizado a constituir, imaginariamente, as capacidades do sujeito, sejam técnicas, sejam de sociabilidade. Por isso, na disputa por outras significações, "Educacional" significa uma "tendência de mercado" e uma "solução inovadora" que se vale da instrumentalização do digital para adequar o sujeito trabalhador.

\section{REFERÊNCIAS}

AIRES, R.; MOREIRA, F.; FREIRE, P. Indústria 4.0: desafios e tendências para a gestão do conhecimento. SUCEG - Seminário de Universidade Corporativa e Escolas de Governo, [S.I.], v. 1, n. 1, p. 224-247, dez. 2017. Disponível em: http://anais.suceg.ufsc.br/index.php/ suceg/article/view/49. Acesso em: 30 set. 2019.

AUROUX, S. A revolução tecnológica da gramatização. Tradução Eni Puccinelli Orlandi. Campinas: UNICAMP, 1992.

GUIMARÃES, E. A enumeração: funcionamento enunciativo e sentido. Cadernos de Estudos Linguísticos, Campinas, n. 1, p. 49-69, ago. 1978.

HAROCHE, C.; HENRY, P.; PÊCHEUX, M. A semântica e o corte saussureano: língua, linguagem, discurso. Tradução Roberto Leiser Baronas e Fábio César Montanheiro. Revista Linguagem, São Carlos, n. 3, out./nov. 2008. Disponível em: www.letras.ufscar.br/ linguasagem/edição 03/tradução-hph.php. Acesso em: 30 set. 2019. 
MORELLO, R. Política científica e linguagens de tecnologia. In: MORELLO, R. (org.). Giros na Cidade: materialidade do espaço. Campinas: Labeurb/Nudecri-UNICAMP, 2004. p. 31-39.

ORLANDI, E. P. Análise de Discurso. In: ORLANDI, E. P.; LAGAZZI-RODRIGUES, S. (org.). Discurso e Textualidade. 3. ed. Campinas: Pontes, 2015. p. 13-37.

ORLANDI, E. P. Ponto Final: Interdiscurso, Incompletude, Textualização. In: ORLANDI, E. P. Discurso e Texto: formulação e Circulação dos Sentidos. 4. ed. Campinas: Pontes, 2012. p. 109-127.

ORLANDI, E. P. O discurso sobre a língua no período Vargas (Estado Novo - 1937/1945). In: ORLANDI, E. P. Língua brasileira e outras histórias - discurso sobre a língua e ensino no Brasil. Campinas: Editora RG, 2009. p. 113-121.

ORLANDI, E. P. Ler a Cidade: o arquivo e a memória. In: ORLANDI, E. P. (org.). Para uma enciclopédia da cidade. Campinas: Pontes, Labeurb/UNICAMP, 2003. p. 7-21.

PÊCHEUX, M. Metáfora e Interdiscurso. In: PÊCHEUX, M. Análise de Discurso. Textos escolhidos por: Eni Puccinelli Orlandi. 4. ed. Campinas: Pontes, 2015a. p. 151-163.

PÊCHEUX, M. Metáfora e Interdiscurso. In: ACHARD, P. et al. tradução e introdução José Horta Nunes. Papel da memória. 4. ed. Campinas: Pontes, 2015b. p. 43-53.

PÊCHEUX, M. O discurso - Estrutura ou acontecimento. Tradução Eni Orlandi. 5. ed. Campinas: Pontes, 2008.

PFEIFFER, C. C. Definir (,) um percurso. In: ORLANDI, E. P. (org.). Para uma enciclopédia da cidade. Campinas: Pontes, Labeurb/UNICAMP, 2003. p. 105-121.

PFEIFFER, C. C. Políticas públicas: educação e linguagem. Cadernos de Estudos Linguísticos, v. 53, n. 2, p. 149-156, jul./dez. 2011. Disponível em: https://doi.org/10.20396/ cel.v53i2.8636984. Acesso em: 30 set. 2019.

SILVA, M. V. História da alfabetização no Brasil: sentidos e sujeito da escolarização. Campinas: Editora da UNICAMP, 2015. 